\title{
Hi-Nicalon fiber-reinforced celsian matrix composites: Influence of interface modification
}

\author{
Narottam P. Bansal ${ }^{\text {a) }}$ and Jeffrey I. Eldridge \\ National Aeronautics and Space Administration, Lewis Research Center, Cleveland, Ohio 44135-3191
}

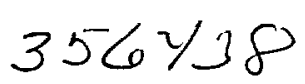

(Received 29 May 1997; accepted 10 October 1997)

Unidirectional celsian matrix composites having $42-45$ vol \% of uncoated or BN-SiC coated Hi-Nicalon fibers were tested in three-point bend at room temperature. The uncoated fiber-reinforced composites showed catastrophic failure with strength of $210 \pm$ $35 \mathrm{MPa}$ and a flat fracture surface. In contrast, composites reinforced with coated fibers exhibited graceful failure with extensive fiber pullout. Values of first matrix cracking stress and strain were $435 \pm 35 \mathrm{MPa}$ and $0.27 \pm 0.01 \%$, respectively, with ultimate strength as high as $960 \mathrm{MPa}$. The elastic Young modulus of the uncoated and coated fiber-reinforced composites were $184 \pm 4 \mathrm{GPa}$ and $165 \pm 5 \mathrm{GPa}$, respectively. Fiber push-through tests and microscopic examination indicated no chemical reaction at the uncoated or coated fiber-matrix interface. The low strength of composite with uncoated fibers is due to degradation of the fiber strength from mechanical damage during processing. Because both the coated- and uncoated-fiber-reinforced composites exhibited weak interfaces, the beneficial effect of the $\mathrm{BN}-\mathrm{SiC}$ dual layer is primarily the protection of fibers from mechanical damage during processing.

\section{INTRODUCTION}

Fiber-reinforced ceramic matrix composites are being developed ${ }^{1,2}$ for high-temperature structural applications in aerospace, energy conservation, power generation, nuclear, petrochemical, and other industries. A number of glass and glass-ceramic matrices reinforced with continuous fibers having high strength and high modulus have been reported ${ }^{1,2}$ over the last two decades. Monoclinic celsian is a refractory material showing good oxidation resistance, phase stability up to $\sim 1600{ }^{\circ} \mathrm{C}$, and low values of dielectric constant and loss tangent. It is, therefore, a promising matrix material ${ }^{3-5}$ for reinforcement with ceramic fibers for high temperature structural composites. Processing and properties of celsian glassceramic matrix composites reinforced with large diameter CVD SiC SCS-6 monofilaments, ${ }^{6-8}$ multifilament small diameter Nicalon, ${ }^{9}$ and HPZ fibers ${ }^{10}$ have been described earlier. The details of fabrication of Hi-Nicalon fiber-reinforced celsian matrix composites have been reported elsewhere. ${ }^{11}$ In order to achieve stoichiometric composition, the celsian matrix was synthesized ${ }^{3,11}$ by solid-state reaction between the metal oxides.

The objective of the present study was to investigate the effects of fiber-matrix interface modification on the properties of small diameter Hi-Nicalon fiberreinforced celsian matrix composites. Room temperature mechanical properties of uncoated and $\mathrm{BN}-\mathrm{SiC}$ coated Hi-Nicalon fiber-reinforced celsian composites were measured in three-point flexure. The function of the

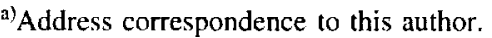

BN interfacial layer is to act as a weak, crack-deflecting phase, while that of the $\mathrm{SiC}$ overcoat is to act as a barrier to diffusion of boron from BN into the BSAS oxide matrix and also to diffusion of matrix elements into the fiber. The fiber/matrix interface was characterized by microscopy and also by fiber push-through tests.

\section{MATERIALS AND EXPERIMENTAL METHODS}

Polymer derived Hi-Nicalon fiber tows (1800 denier, 500 filaments/tow) with low oxygen content from Nippon Carbon Co. were used as the reinforcement. According to the manufacturer, these fibers ${ }^{12,13}$ have an average diameter of $\sim 14 \mu \mathrm{m}$ and chemical composition (wt. \%) of $62.4 \% \mathrm{Si}, 37.1 \% \mathrm{C}$, and $0.5 \% \mathrm{O}$ with a $\mathrm{C} / \mathrm{Si}$ atomic ratio of $\sim 1.39$. The Hi-Nicalon fibers mainly consist of $\mathrm{SiC}$ microcrystals and amorphous carbon and show room temperature tensile strength of $\sim 2.8 \mathrm{GPa}$ and elastic modulus of $270 \mathrm{GPa}$. Both as-received $\mathrm{Hi}$ Nicalon fibers as well as those having a dual surface layer of $\mathrm{BN}$ overcoated with $\mathrm{SiC}$ were used. The fiber surface coatings were applied by a commercial vendor using a continuous chemical vapor deposition (CVD) reactor. The BN coating was deposited at $\sim 1000{ }^{\circ} \mathrm{C}$ utilizing a proprietary precursor and was amorphous to partly turbostratic in nature. $\mathrm{A}$ thin overcoating of $\mathrm{SiC}$ was also deposited by CVD to the BN-coated fibers. The $\mathrm{SiC}$ layer was crystalline. The nominal coating thicknesses were $0.4 \mu \mathrm{m}$ for $\mathrm{BN}$ and $0.3 \mu \mathrm{m}$ for $\mathrm{SiC}$. The polyvinyl alcohol (PVA) sizing on the as-received fibers was burned off in air by passing through a tube furnace. 
The fiber-reinforced composites were fabricated by impregnation of the fiber tows with the matrix slurry as described earlier." The precursor to the celsian matrix of $0.75 \mathrm{BaO}-0.25 \mathrm{SrO}-\mathrm{Al}_{2} \mathrm{O}_{3}-2 \mathrm{SiO}_{2}$ composition was synthesized by a solid-state reaction method as reported elsewhere. ${ }^{3}$ The precursor powder consisted ${ }^{3}$ of mainly $\mathrm{SiO}_{2}\left(\alpha\right.$-quartz) and $\mathrm{BaAl}_{2} \mathrm{O}_{4}$ phases with small amounts of $\mathrm{Ba}_{2} \mathrm{SiO}_{4}, \alpha-\mathrm{Al}_{2} \mathrm{O}_{3}$, and $\mathrm{Ba}_{2} \mathrm{Sr}_{2} \mathrm{Al}_{2} \mathrm{O}_{7}$ also present. This powder was made into a slurry by dispersing in an organic solvent and ball milling along with various organic additives which acted as binder, surfactant, deflocculant, and plasticizer. Tows of BN$\mathrm{SiC}$ coated or as-received, but desized, Hi-Nicalon fibers were spread using rollers and coated with the matrix precursor by passing through a slurry. Excess slurry was squeezed out of the fiber tow before winding it (26 fiber tows/inch) on a rotating drum. The prepreg tape was allowed to dry and cut to size. Unidirectional fiberreinforced composites were prepared by prepreg tape lay up (12 plies) and warm pressing which resulted in a "green" composite. The fugitive organics were slowly burned out of the sample in air, followed by hot pressing under vacuum in a graphite die. The resulting composites were almost fully dense. The oxide precursor was converted into the desired monoclinic celsian phase in situ during hot pressing. The hot-pressed, fiber-reinforced composite panel was surface polished and sliced into test bars $(\sim 50.4 \mathrm{~mm} \times 6.4 \mathrm{~mm} \times 1.9 \mathrm{~mm})$ for mechanical testing.

$\mathrm{X}$-ray diffraction (XRD) patterns were recorded at room temperature using a step scan procedure $\left(0.02^{\circ} / 2 \theta\right.$ step, time per step 0.5 or $1 \mathrm{~s}$ ) on a Philips ADP3600 automated diffractometer equipped with a crystal monochromator employing $\mathrm{Cu} \mathrm{K}_{\alpha}$ radiation. Density was measured from dimensions and mass as well as by the Archimedes method. Microstructures of the polished cross sections and fracture surfaces were observed in an optical microscope as well as by a JEOL JSM-840A scanning electron microscope (SEM). Prior to analysis, a thin carbon coating was evaporated onto the SEM specimens to provide for electrical conductivity.

Mechanical properties were determined from stressstrain curves recorded in three-point flexure using an Instron machine at a crosshead speed of $0.127 \mathrm{~cm} / \mathrm{min}$ $(0.05 \mathrm{in} . / \mathrm{min})$ and support span $(L)$ of $40 \mathrm{~mm}$. Strain gauges were glued to the tensile surfaces of the flexure test bars. The first matrix cracking stress was calculated from the stress-strain curves where the curve deviates from linearity. The elastic modulus of the composite was determined from the linear portion of the stressstrain curve.

Fiber push-through tests were performed using a desktop apparatus previously described, ${ }^{14}$ but with the addition of a pair of capacitance displacement gauges for displacement measurements. Thin sections of the com- posites, cut normal to the fiber axis with a diamond saw, and polished down to a $0.1 \mu \mathrm{m}$ finish on both top and bottom faces were tested. Fibers aligned above $300 \mu \mathrm{m}$ wide channels in the sample support were pushed with a conical diamond indenter ( $70^{\circ}$ included angle) with a $10 \mu \mathrm{m}$ diameter flat base. Load-displacement and acoustic emission measurements were collected at $50 \mathrm{~ms}$ intervals by a computer. The push-through curves consisted of applied load plotted versus measured displacement (averaged from two symmetrically placed capacitance gauges). Over 20 fibers, selected from different regions of the specimen, were pushed out. Tests were performed at room temperature in ambient atmosphere (relative humidity $\sim 50 \%$ ).

\section{RESULTS AND DISCUSSION}

\section{A. Microstructural analysis}

SEM micrographs taken from the polished cross sections of the unidirectional composites containing uncoated and the BN-SiC coated Hi-Nicalon fibers are shown in Fig. 1. Uniform fiber distribution and good matrix infiltration within the fiber tows, as evident in Fig. 1, result in high composite density. Occasional pores, particularly within the fiber tows, are present. The manufacturer reports an average fiber diameter of $\sim 14 \mu \mathrm{m}$, but a large variation in the diameter of the filaments within a fiber tow can be seen. The $\mathrm{SiC}$ surface coating has been detached from some of the fibers during metallography or composite processing, which may lead to adverse reactions between the fibers and the oxide matrix at high temperature resulting in strong fibermatrix bonding.

XRD patterns taken from the polished surface of the hot pressed composites indicated the presence of monoclinic celsian as the only crystalline phase. This implies that the desired, thermodynamically stable, monoclinic celsian phase is formed in situ, from the mixed oxide precursor, during hot pressing of the composite. The undesired hexacelsian phase was not detected from XRD. However, the presence of a second matrix phase, not yet identified, is evident from the micrographs of Fig. 1. The fraction of this phase should be less than $-5 \%$ as it was not detected by XRD.

\section{B. Mechanical properties}

The fiber volume fraction in the hot-pressed composite panels was calculated to be $0.42-0.45$. Typical stress-strain curves recorded in three-point flexure of the composites reinforced with uncoated and $\mathrm{BN}-\mathrm{SiC}$ coated Hi-Nicalon fibers are shown in Figs. 2 and 3, respectively. The stress-strain curve for a hot-pressed BSAS monolith is also shown for comparison. The monolith shows a modulus of $96 \mathrm{GPa}$, flexural strength of $131 \mathrm{MPa}$, and fails in a brittle mode as expected. 

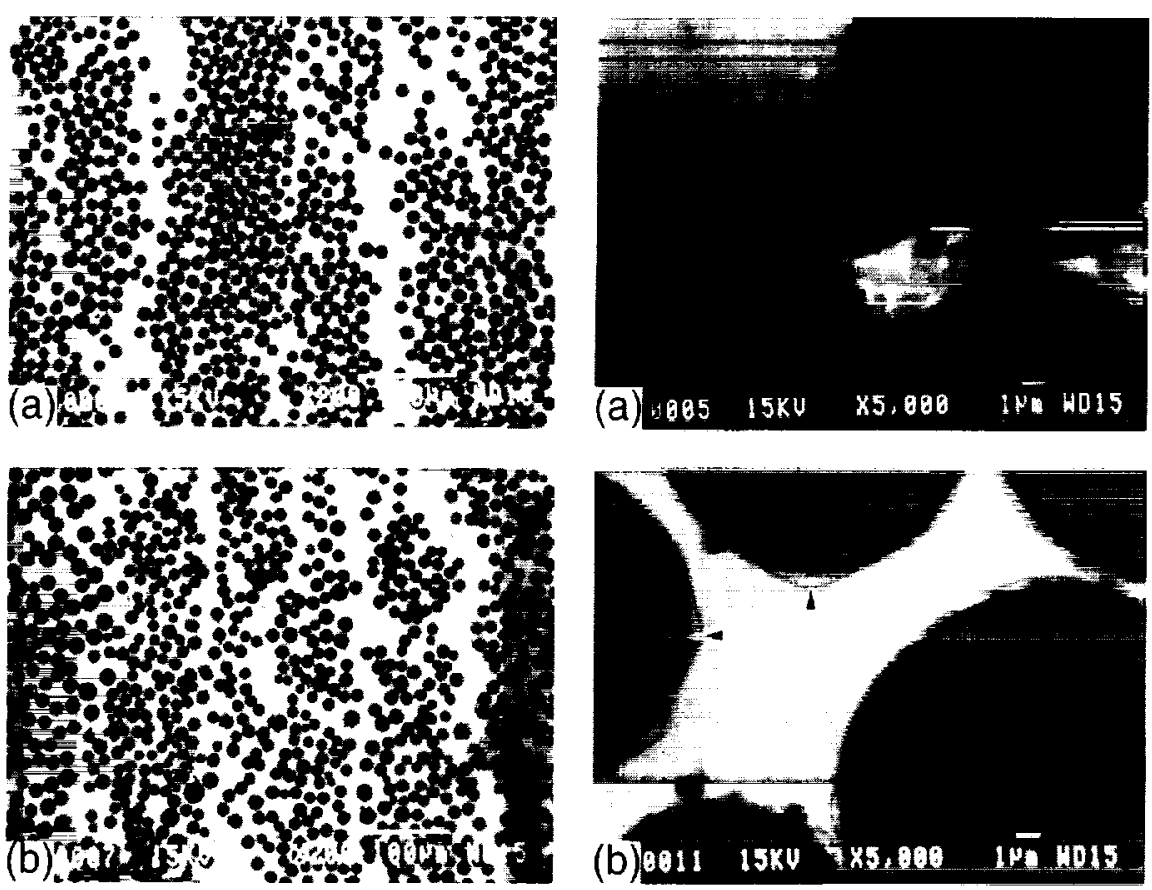

FIG. 1. SEM micrographs showing the polished cross section of unidirectional (a) Hi-Nicalon(uncoated)/BSAS composite and (b) Hi-Nicalon/BN/SiC/BSAS composite.

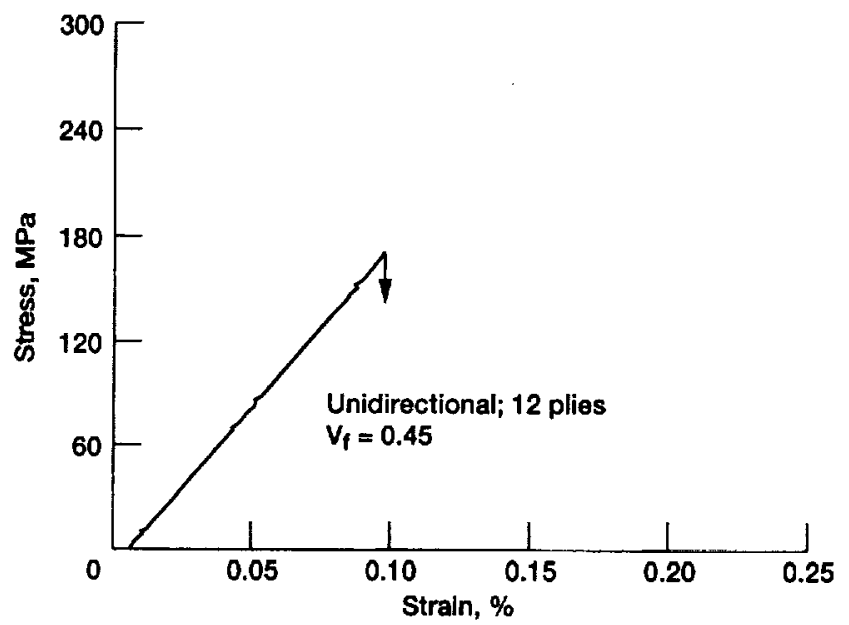

FIG. 2. Stress-strain curve for a unidirectional Hi-Nicalon(uncoated)/ BSAS composite.

The uncoated fiber-reinforced composite also shows catastrophic failure with flexure strength of $180-245 \mathrm{MPa}$ and elastic modulus of $\sim 184 \pm 4 \mathrm{GPa}$. In contrast, the BN-SiC coated fiber-reinforced composite shows graceful failure. The values of first matrix cracking stress, $\sigma_{m c}$, and the first matrix cracking strain, $\epsilon_{m c}$, were measure to be $435 \pm 35 \mathrm{MPa}$ and $0.27 \pm 0.01 \%$, respectively. The elastic modulus was calculated to be $\sim 165 \pm 5 \mathrm{GPa}$. Composite ultimate strength as high as $960 \mathrm{MPa}$ has been observed. Room temperature mechanical properties of the various composites of this study are given in Table I. The composite containing BN-SiC

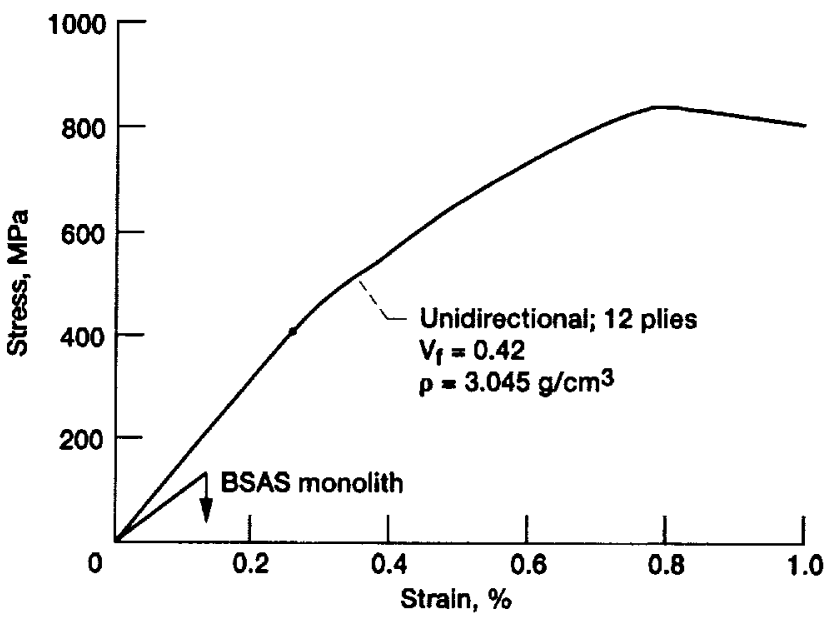

FIG. 3. Stress-strain curves for BSAS monolith and a unidirectional Hi-Nicalon/BN/SiC/BSAS composite.

coated fibers had a lower modulus than the uncoated fiber-reinforced composite due to the presence of the BN layer.

SEM micrographs of fracture surfaces of the uncoated and BN-SiC coated fiber-reinforced composites, after the three-point flexure tests, are shown in Figs. 4 and 5, respectively. Extensive long lengths of fiber pullout are observed in the Hi-Nicalon/BN/SiC/BSAS composite, indicating toughening behavior. In contrast, the fracture surface of the uncoated fiber-reinforced composite shows little pullout consistent with the observed catastrophic failure. One possible reason for this behav- 
TABLE I. Room temperature mechanical properties ${ }^{\mathrm{a}}$ of Hi-Nicalon fiber-reinforced $\mathrm{Ba}_{0.75} \mathrm{Sr}_{0.25} \mathrm{Al}_{2} \mathrm{Si}_{2} \mathrm{O}_{8}$ celsian composites (unidirectional; 12 plies).

\begin{tabular}{|c|c|c|c|c|c|c|c|c|}
\hline Sample no. & $\begin{array}{c}\text { Fiber } \\
\text { coating }\end{array}$ & $\begin{array}{c}\text { Fiber } \\
\text { content, } V_{f}\end{array}$ & $\begin{array}{c}\text { Density, } \rho \\
\left(\mathrm{g} / \mathrm{cm}^{3}\right)\end{array}$ & $\begin{array}{c}\text { Elastic } \\
\text { modulus, } E \\
(\mathrm{GPa})\end{array}$ & $\begin{array}{c}\text { Yield stress, } \\
\sigma_{y}(\mathrm{MPa}) \\
\end{array}$ & $\begin{array}{c}\text { Yield strain, } \\
\epsilon_{y}(\%)\end{array}$ & $\begin{array}{c}\text { Ultimate } \\
\text { stress, } \sigma_{u} \\
(\mathrm{MPa})\end{array}$ & $\begin{array}{c}\text { Ultimate } \\
\text { strain, } \epsilon_{u}(\%)\end{array}$ \\
\hline \multirow[t]{2}{*}{ HI-NIC-BSAS-9-13-95 } & \multirow[t]{2}{*}{ None } & \multirow[t]{2}{*}{0.45} & \multirow[t]{2}{*}{2.90} & 183 & $\cdots$ & $\cdots$ & 202 & 0.110 \\
\hline & & & & 188 & $\cdots$ & $\cdots$ & 215 & 0.115 \\
\hline \multirow[t]{2}{*}{ HI-BSAS-9-26-95 } & \multirow[t]{2}{*}{ None } & \multirow[t]{2}{*}{0.42} & \multirow[t]{2}{*}{2.99} & 181 & .. & $\cdots$ & 181 & 0.100 \\
\hline & & & & 184 & $\cdots$ & $\cdots$ & 246 & 0.133 \\
\hline \multirow[t]{2}{*}{ HI-BSAS-10-11-95 } & \multirow[t]{2}{*}{ None } & \multirow[t]{2}{*}{0.45} & \multirow[t]{2}{*}{3.01} & 184 & $\cdots$ & $\cdots$ & 172 & 0.096 \\
\hline & & & & 186 & $\cdots$ & $\cdots$ & 219 & 0.117 \\
\hline \multirow[t]{2}{*}{ HI-NIC-BSAS-1-29-96 } & \multirow[t]{2}{*}{$\mathrm{BN}-\mathrm{SiC}$} & \multirow[t]{2}{*}{0.43} & \multirow[t]{2}{*}{3.05} & 168 & 468 & 0.283 & 958 & 0.661 \\
\hline & & & & 159 & 405 & 0.258 & 850 & 0.801 \\
\hline \multirow{2}{*}{ HI-NIC-BSAS-1-31-96 } & \multirow[t]{2}{*}{$\mathrm{BN}-\mathrm{SiC}$} & \multirow[t]{2}{*}{0.43} & \multirow[t]{2}{*}{3.09} & 170 & 436 & 0.264 & 862 & 0.583 \\
\hline & & & & 165 & 464 & 0.283 & 960 & 0.771 \\
\hline
\end{tabular}

${ }^{\text {a }}$ Measured in 3-point flexure.

ior could be strong bonding of the uncoated fibers with the oxide matrix during hot pressing. Another possible explanation for such a low strength of the uncoated fiberreinforced composites could be mechanical damage to the fibers during composite processing, resulting in fiber strength degradation.

\section{Fiber-matrlx interface}

For tough composites, the fiber-matrix interface must be sufficiently weak to allow debonding at the interface, yet strong enough for effective load transfer from the matrix to the fiber. To help understand the large differences observed in the mechanical behavior of the two composites with different interfaces, differences in fiber debonding and frictional sliding stresses at the fiber-matrix interface were evaluated.

Figure 6 shows typical fiber push-through load/ displacement curves, along with detected acoustic emission, for the composites reinforced with uncoated and $\mathrm{BN}-\mathrm{SiC}$ coated fibers. Both plots show features typical for continuous progressive debonding. ${ }^{15-17}$ Each shows two debonding events that can be attributed to debond initiation and debond completion. ${ }^{18.19}$ The initial debonding event, associated with initial displacement of the top fiber end, occurs where the load displacement curve first deviates from linearity (with a simultaneous small acoustic emission event); this corresponds to debond initiation and the corresponding applied load is labeled $P_{\text {initial debond }}$. After this, the load/displacement curve continues with a lower slope as the debonded length of interface propagates under increasing load until an abrupt load decrease (accompanied by a large acoustic emission event) is observed corresponding to debonding of the entire fiber length. The peak load attained immediately preceding debond completion is labeled

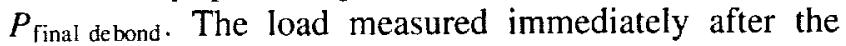
load drop is due solely to frictional resistance to sliding of the entire fiber length and is labeled $P_{\text {friction }}$. Similar experimental results have also been observed ${ }^{18,19}$ for other fiber-reinforced composite systems. On continued fiber sliding, the frictional sliding load was fairly stable for the uncoated fiber reinforced composite [Fig. 6(a)] whereas the frictional sliding loads tended to increase for the $\mathrm{BN}-\mathrm{SiC}$ coated fiber reinforced composite [Fig. 6(b)].

Table II summarizes the results of the push-through tests, giving the $95 \%$ confidence interval about each mean value. Because of the variation in fiber diameters, applied compressive stress, $\sigma=P /\left(\pi r_{\text {fiber }}^{2}\right)$, is reported rather than applied load, $P$, for fiber-matrix debonding. The average interfacial frictional sliding stress, $\tau_{\text {friction }}$, was calculated by simply dividing the applied load, $P_{\text {friction }}$, by the nominal contact area between the fiber and the matrix:

$$
\tau_{\text {friction }}=\frac{P_{\text {friction }}}{2 \pi r_{\text {fiber }} t}
$$

where $r_{\text {fiber }}$ is the fiber radius, and $t$ is the specimen thickness. This equation assumes a uniform interfacial

TABLE II. Summary of fiber push-through results. ${ }^{a}$

\begin{tabular}{lccccc}
\hline \hline \multicolumn{1}{c}{ Specimen } & Thickness $(\mathrm{mm})$ & No. of tests & $\sigma_{\text {initial debmid }}(\mathrm{GPa})$ & $\sigma_{\text {final debond }}(\mathrm{GPa})$ & $\tau_{\text {friction }}(\mathrm{MPa})$ \\
\hline No fiber coating & 0.20 & 24 & $1.97 \pm 0.33$ & $2.93 \pm 0.58$ & $30.8 \pm 6.9$ \\
BN-SiC fiber coating & 0.21 & 30 & $1.48 \pm 0.20$ & $2.84 \pm 0.48$ & $52.1 \pm 9.9$ \\
\hline \hline
\end{tabular}

a \pm indicates $95 \%$ confidence interval about mean value. 

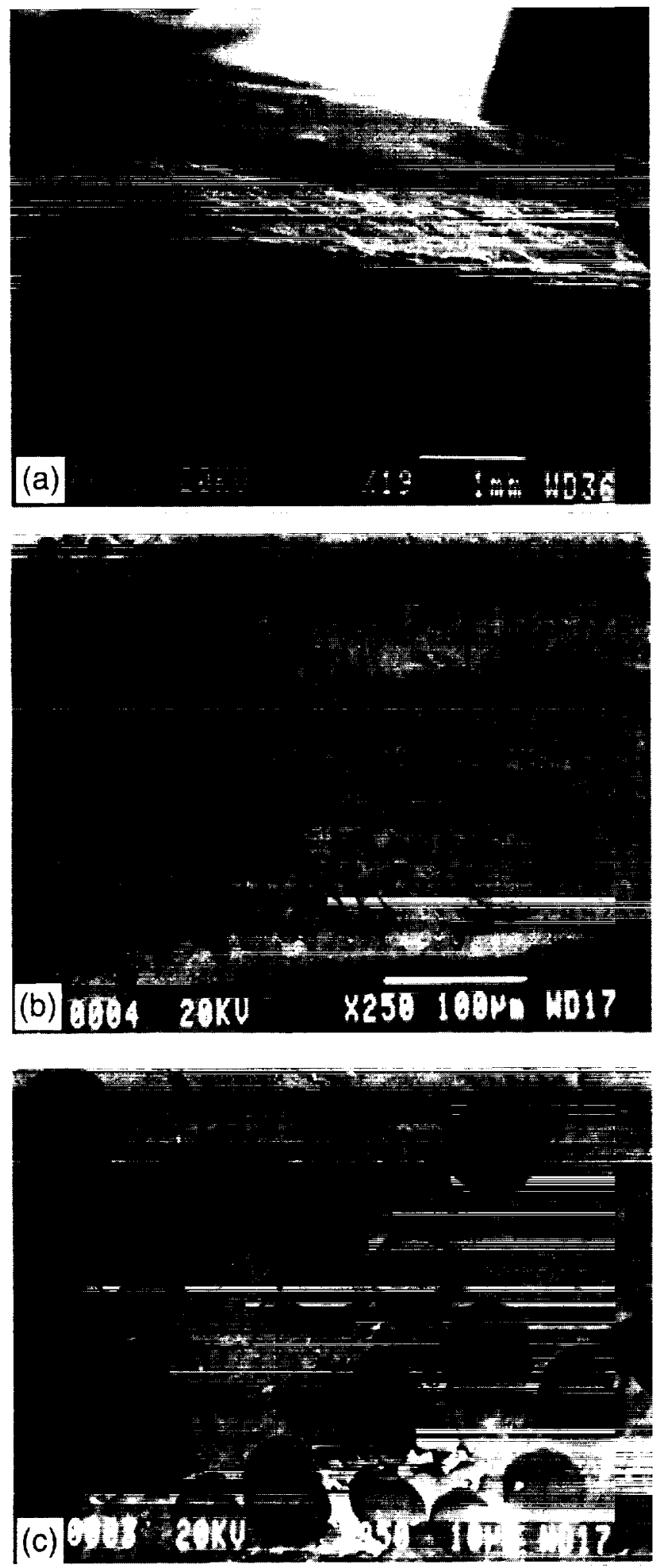

FIG. 4. (a-c) SEM micrographs from the fracture surface of a unidirectional Hi-Nicalon(uncoated)/BSAS composite.

shear stress along the length of the fiber/matrix interface when the entire length of the fiber is sliding. Further detailed analysis of cyclic fiber push-in tests of much
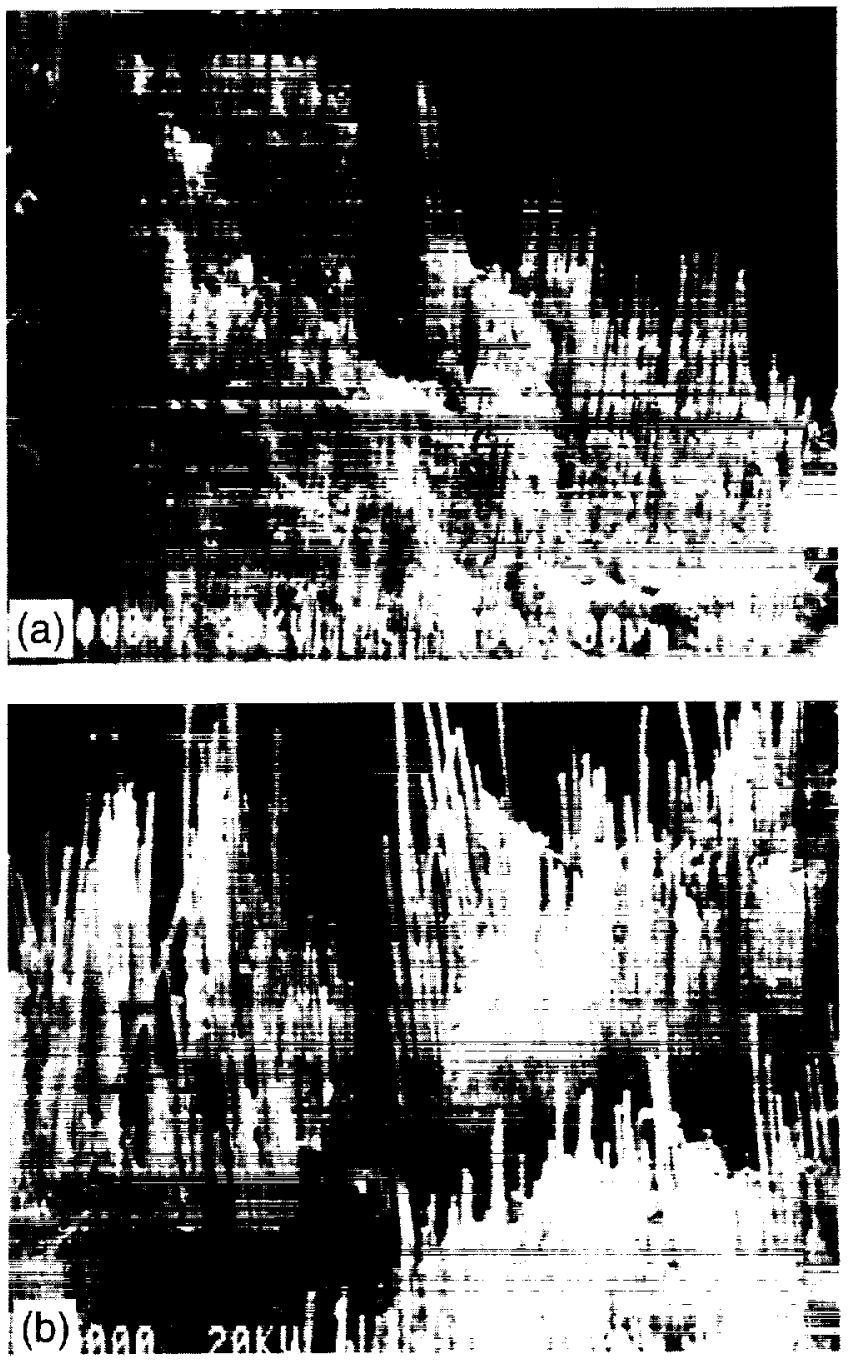

FIG. 5. (a,b) SEM micrographs from the fracture surface of a unidirectional $\mathrm{Hi}$-Nicalon/BN/SiC/BSAS composite showing extensive fiber pullout.

thicker specimens is now being carried out and the results will be reported elsewhere.

Results in Table II surprisingly indicate that the presence of the BN-SiC coating did not have a very pronounced effect on the fiber push-through behavior. Compared to the composite with uncoated fibers, the composite with BN-SiC coated fibers showed a very modest decrease in the applied stress necessary for debond initiation ( $\sigma_{\text {initial debond }}$ ), and no significant difference in the peak debond stress $\left(\sigma_{\text {final debond }}\right)$. Also $\tau_{\text {friction }}$ values indicate that the uncoated fibers slid more easily after debonding than the coated fibers. This is surprising because the uncoated fiber-reinforced composite showed brittle failure, suggesting a strongly bonded fiber/matrix interface. The most pronounced effect of the $\mathrm{BN}-\mathrm{SiC}$ fiber coating was the continuous increase in $\tau_{\text {friction }}$ with additional fiber sliding, whereas $\tau_{\text {friction }}$ values for the uncoated fiber-reinforced composite remain relatively 

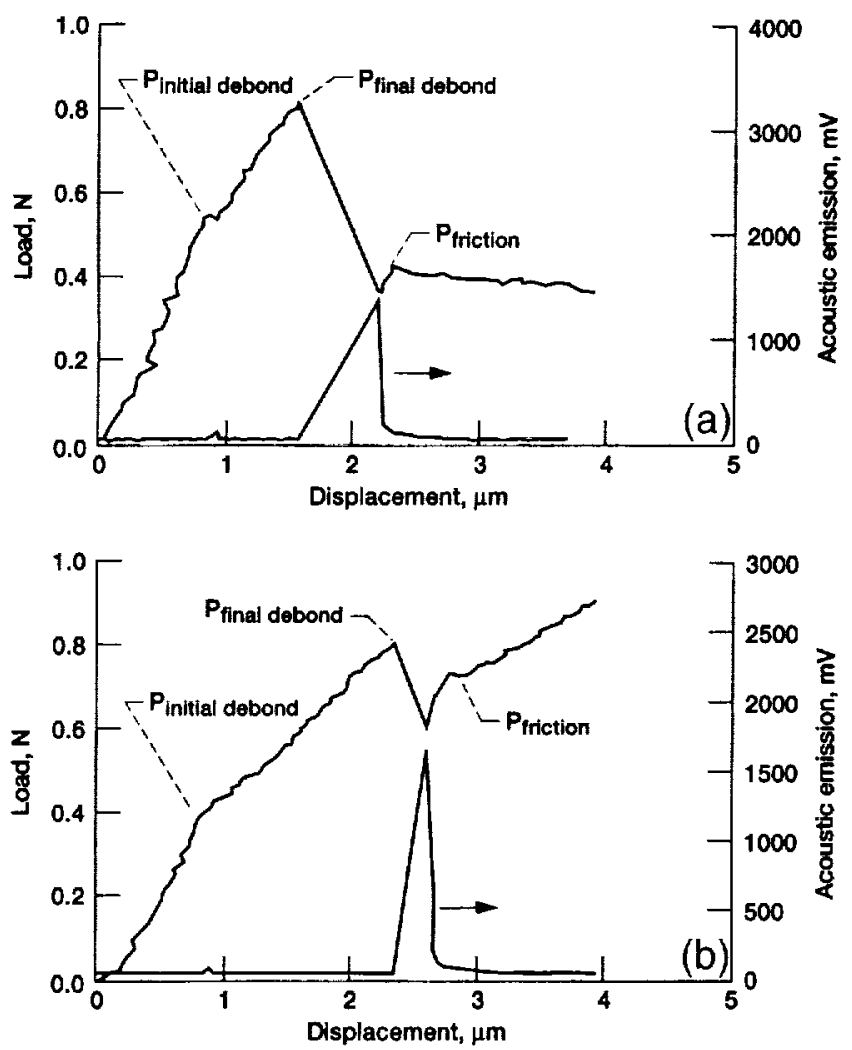

FIG. 6. Typical load versus displacement curves for fiber pushout in Hi-Nicalon/BSAS composites: (a) uncoated fiber and (b) BN-SiC coated fiber composites. Also shown is the acoustic emission signal.

constant. The increase in $\tau_{\text {friction }}$ with continued fiber sliding for the $\mathrm{BN}-\mathrm{SiC}$ coated fiber-reinforced composite suggests the occurrence of interfacial wear during fiber sliding. ${ }^{20} \mathrm{~A}$ buildup of wear debris between the sliding fiber and matrix would tend to make fiber sliding increasingly difficult. This explanation is supported by SEM micrographs (Fig. 7) of the pushed-in coated fibers that consistently showed debris along the exposed matrixhole-wall resulting from the tearing/shredding of the fiber coating. In contrast, inspection of the pushed-in uncoated fibers in the SEM (Fig. 8) showed no such debris.

There was no strong reaction between the uncoated Hi-Nicalon fibers and the BSAS matrix during processing, as supported by the modest applied stresses required to initiate fiber debonding (Table II) as well as the clean fiber/matrix separation observed in SEM micrographs of pushed-through fibers. Because the subtle differences in fiber/matrix bonding in the two composites cannot explain the low strength and flat fracture surface of the uncoated fiber-reinforced composite, the possibility of fiber degradation from mechanical surface damage during processing was investigated. While the $\mathrm{BN}-\mathrm{SiC}$ dual layer was applied to promote a weak interface, this coating may more importantly protect the fiber surface from mechanical damage during processing. To substantiate this, tensile strengths of the fibers extracted from the composites by leaching away the matrix in $\mathrm{HF}$ acid were measured. ${ }^{21}$ The BN/SiC coated fibers extracted from the FRC gave a tensile strength of $2.38 \pm$ $0.4 \mathrm{GPa}$ whereas the uncoated fibers fragmented into small pieces during extraction. In contrast, as-received Hi-Nicalon fibers after a similar treatment with HF acid showed no strength degradation. These results confirm that the uncoated Hi-Nicalon fibers have suffered severe mechanical damage during composite processing. In comparison, unidirectional $\mathrm{Hi}$-Nicalon (uncoated) fiberreinforced lithium aluminosilicate (LAS) glass-ceramic composites containing $50 \mathrm{vol} \%$ fibers and processed at $1360{ }^{\circ} \mathrm{C}$ for 40 min exhibited ${ }^{22}$ room temperature threepoint flexural strength of $1158 \mathrm{MPa}$. The fibers extracted from the composite by dissolving away the LAS matrix in HF acid showed only $20-25 \%$ reduction in tensile strength. ${ }^{22}$ Similar strength loss has also been observed for Ceramic Grade Nicalon fibers extracted from LAS glass-ceramic matrix composites. ${ }^{23}$ The large difference observed in the strengths of the LAS and BSAS matrix composites reinforced with uncoated Hi-Nicalon fibers is due to the differences in the processing of the two composites. The LAS composites are hot pressed for a short time just above the melting point of the matrix, making use of the viscous flow of glass for densification.

\section{SUMMARY OF RESULTS}

Uncoated and $\mathrm{BN}-\mathrm{SiC}$ coated Hi-Nicalon fiberreinforced monoclinic celsian matrix composites have been produced by impregnation of the matrix slurry into fiber tows followed by hot pressing. Almost fully dense unidirectional composites containing $42-45 \mathrm{vol} \%$ of fibers have been obtained. The uncoated fiberreinforced composites exhibited monolithic-like failure with three-point flexural strength of 180-245 MPa. In contrast, the composites containing coated fibers showed graceful failure with a first matrix cracking stress of $435 \pm 35 \mathrm{MPa}$ and an ultimate strength as high as $960 \mathrm{MPa}$. Values of the elastic Young's modulus were measured to be $\sim 184$ and $\sim 165 \mathrm{GPa}$ for the composites containing uncoated and BN-SiC coated fibers, respectively. No chemical reaction was observed between the fiber and the matrix during composite processing as indicated by modest stresses required to initiate fiber debonding as well as clean and smooth surfaces of the pushed out fibers.

\section{CONCLUSIONS AND FUTURE RESEARCH}

It may be concluded that reinforcement of the monoclinic celsian with $\mathrm{BN}-\mathrm{SiC}$ coated $\mathrm{Hi}-\mathrm{Nicalon}$ fibers results in strong, tough, and almost fully dense composites. However, reinforcement with the uncoated HiNicalon fibers yields a weak composite material due to 

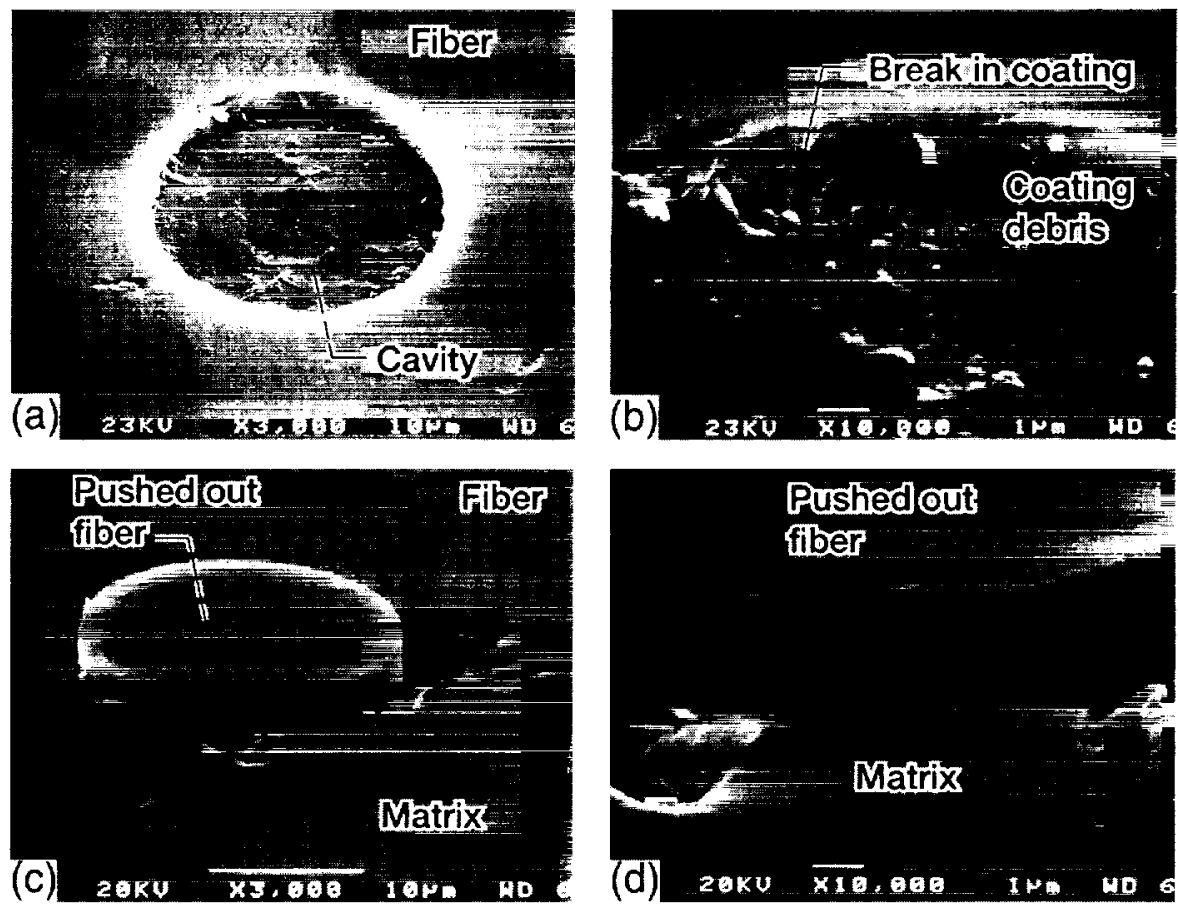

FIG. 7. SEM micrographs showing (a,b) cavity resulting from pushed out fiber and (c,d) pushed out fiber in Hi-Nicalon/BN/SiC/BSAS composite.
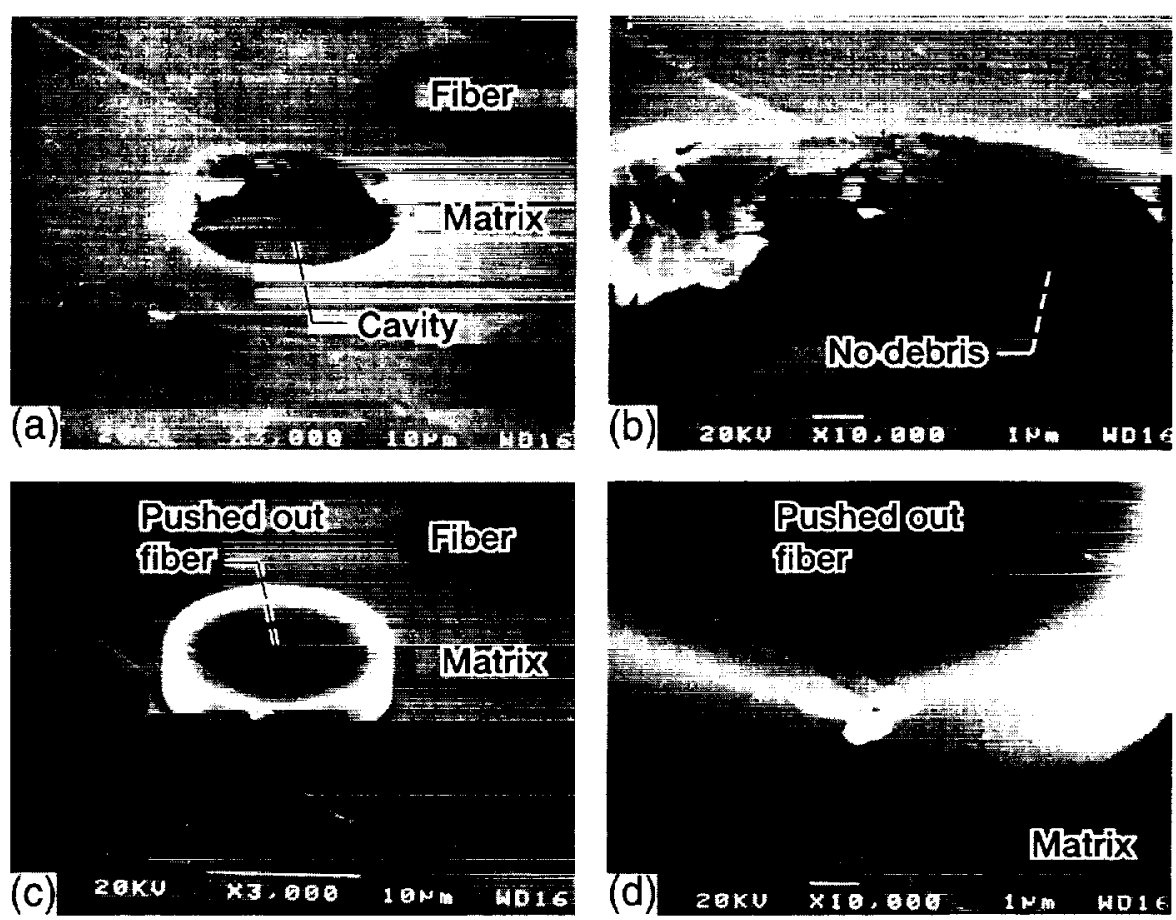

FIG. 8. SEM micrographs showing (a,b) cavity resulting from pushed out fiber and (c,d) pushed out fiber in Hi-Nicalon(uncoated)/BSAS composite.

severe strength degradation of the fibers from mechanical surface damage during hot pressing. While both the uncoated and BN-SiC coated fibers provide a weak interface, the BN layer is needed to protect the fibers from mechanical damage. The increased frictional sliding stresses observed for the $\mathrm{BN}-\mathrm{SiC}$ coated fibers will result in a more effective load transfer from the matrix to the fiber. 
Future research will involve the investigation of the mechanical properties (tensile strength, creep, fatigue, etc.) of unidirectional and cross-ply Hi-Nicalon/BN/SiC/celsian composites at elevated temperatures in air and inert environments. The effects of high temperature annealing on room temperature residual strength and fiber-matrix interface bonding will also be studied.

\section{ACKNOWLEDGMENTS}

Thanks are due to John Setlock for composite processing, to Ron Phillips for flexure strength measurements, and to Ralph Garlick for x-ray diffraction analysis.

\section{REFERENCES}

1. K. M. Prewo, Glasses and Glass-Ceramics, edited by M. H. Lewis (Chapman and Hall, New York, 1989), pp. 336-368.

2. J.J. Brennan, Fiber Reinforced Ceramic Composites, edited by K. S. Mazdiyasni (Noyes, Park Ridge, NJ, 1990), pp. 222-259.

3. N. P. Bansal, Solid State Synthesis and Properties of Monoclinic Celsian, NASA TM 107355 (1996).

4. N.P. Bansal and C.H. Drummond III, J. Am. Ceram. Soc. 76 (5), $1321-1324$ (1993).

5. N.P. Bansal, M. J. Hyatt, and C. H. Drummond III, Ceram. Eng. Sci. Proc. 12 (7-8), $1222-1234$ (1991)

6. N.P. Bansal, Ceramic Fiber-Reinforced Glass-Ceramic Matrix Composite, U.S. Patent 5,214,004, May 25, 1993.

7. N.P. Bansal, Method of Producing a Ceramic Fiber-Reinforced Glass-Ceramic Matrix Composite, U.S. Patent, 5,281,559, January $25,1994$.
8. N. P. Bansal, Mater. Sci. Eng. A 220 (1-2), $129-139$ (1996).

9. N.P. Bansal, P. McCluskey, G. Linsey, D. Murphy, and G. Levan, Nicalon Fiber-Reinforced Celsian Glass-Ceramic Matrix Composites, Proceedings of Annual HITEMP Review, Cleveland, OH, October 23-25, 1995. NASA CP 10178, Vol. III, pp. 41-1 to 41-14 (1995).

10. N.P. Bansal, Processing and Properties of HPZ Fiber-Reinforced Celsian Glass-Ceramic Matrix Composites (unpublished).

11. N.P. Bansal and J.A. Setlock, Processing of Small Diameter Fiber-Reinforced Celsian Composites, NASA TM 107356 (1996).

12. M. Takeda, J. Sakamoto, Y. Imai, H. Ichikawa, and T. Ishikawa, Ceram. Eng. Sci. Proc. 15 (4), 133-141 (1994).

13. M. Takeda, J. Sakamoto, S. Saeki, Y. Imai, and H. Ichikawa, Ceram. Eng. Sci. Proc. 16 (4), 37-44 (1995)

14. J.I. Eldridge, Desktop Fiber Push-Out Apparatus, NASA TM 105341 (1991)

15. E. Lara-Curzio, M. K. Ferber, and R. A. Lowden, Ceram. Eng Sci. Proc. 15 (5), 989-1000 (1994).

16. E. Lara-Curzio and M. K. Ferber, J. Mater. Sci. 29, 6152-6158 (1995).

17. R. J. Kerans and T. A. Parthasarathy, J. Am. Ceram. Soc. 74 (7), 1586- 1596 (1991)

18. D. A. Koss, M.N. Kallas, and J.R. Hellmann, in Intermetallic Matrix Composites $I I$, edited by D. B. Miracle, D. L. Anton, and J. A. Graves (Mater. Res. Soc. Symp. Proc. 273, Pittsburgh, PA, 1992), pp. 303-313.

19. J. I. Eldridge, R. T. Bhatt, and J. D. Kiser, Ceram. Eng. Sci. Proc. $12(7-8), 1152-1171$ (1991).

20. J. I. Eldridge and B. T. Ebihara, J. Mater. Res. 9, 1035-1042 (1994).

21. N.P. Bansal (unpublished research).

22. W. K. Tredway, Ceram. Eng. Sci. Proc. 17 (4), 291-298 (1996)

23. K. M. Prewo, J. Mater. Sci. 21 (10), 3590-3600 (1986). 